\title{
A comparative corpus-assisted discourse study of the representations of hosts in promotional tourism discourse
}

Article

Accepted Version

Jaworska, S. (2016) A comparative corpus-assisted discourse study of the representations of hosts in promotional tourism discourse. Corpora, 11 (1). pp. 83-111. ISSN 1755-1676 doi: https://doi.org/10.3366/cor.2016.0086 Available at https://centaur.reading.ac.uk/40695/

It is advisable to refer to the publisher's version if you intend to cite from the work. See Guidance on citing.

To link to this article DOI: http://dx.doi.org/10.3366/cor.2016.0086

Publisher: Edinburgh University Press

All outputs in CentAUR are protected by Intellectual Property Rights law, including copyright law. Copyright and IPR is retained by the creators or other copyright holders. Terms and conditions for use of this material are defined in the End User Agreement.

www.reading.ac.uk/centaur

\section{CentAUR}


Central Archive at the University of Reading

Reading's research outputs online 
This is a pre-publication version accepted for Corpora 2016, 11 (1) (in press). Please refer to the published version of this article if you wish to quote from it.

\title{
A comparative corpus-assisted discourse study of the representations of hosts in commercial tourism discourse ${ }^{1}$
}

\begin{abstract}
Most studies concerned with the representations of local people in tourism discourse point to the prevalence of stereotypic images asserting that contemporary tourism perpetuates colonial legacy and gendered discursive practices. This claim has been, to some extent, contested in research that explores representations of hosts in local tourism materials claiming that tourism can also discursively resist the dominant Western imagery. While the evidence for the existence of hegemonic and diverging discourses about the local 'Other' seems compelling, the empirical basis of this research is rather small and often limited to one geographic context. The present study addresses these shortcomings by examining representations of hosts in a larger corpus of promotional tourism materials including texts produced by Western and local tourism industries. The data is investigated using the methodology of Corpus-Assisted Discourse Studies (CADS). By comparing external with internal (self) representations, this study verifies and refines some of the claims on the subject and offers a much more nuanced picture of representations that defies the black and white scenarios proposed in previous research.

Keywords

Tourism, Representations, Corpus-Assisted Discourse Studies (CADS), Stereotype, Colonial Legacy, Gender
\end{abstract}

\section{Introduction}

Since the publication of Hardt-Mautner's (1995) work on the representations of Europe and Krishnamurthy's (1996) study on the discourse of ethnicity and race in the British press, corpus tools and methods have been increasingly used to study discursive constructions of social groups, especially groups that have been marginalised and discriminated. The representations of immigrants, gay people and women in particular have been examined in detail including diachronic as well as contemporary perspectives. Indicative for this corpusbased work is Baker and McEnery's (2005) and Gabrielatos and Baker's (2008) research on the representations of immigrants, refugees and asylum seekers in the British press, Baker's (2004) study on the discourse of homosexuality and Caldas-Coulthard and Moon's (2010) work into the discursive representations of gender in British newspapers. More recent studies include Baker et al. (2013) on the discourse surrounding Islam and Muslims in the British press and Taylor's (2014) comparative research on the discourse of immigration in British

\footnotetext{
${ }^{1}$ I would like to thank Dr Melani Schröter (University of Reading, UK), Dr Sally Hunt (Rhodes University, SA) and Dr Rachelle Vessey (University of Newcastle, UK) for their helpful comments on an earlier version of this manuscript.
} 
This is a pre-publication version accepted for Corpora 2016, 11 (1) (in press). Please refer to the published version of this article if you wish to quote from it.

and Italian newspapers. By combining quantitative corpus techniques with procedures typical for qualitative discourse studies, this research has been invaluable in revealing systematic and also more nuanced patterns of representations that a qualitative analysis alone could not demonstrate. This has contributed to a better understanding of linguistic strategies of 'othering' that underpin nationalist, racist, misogynist and homophobic attitudes.

The present study attempts to add to this strand of research by investigating the ways in which hosts, that is, local people, are represented in larger corpora of promotional tourism discourse. In contrast to previous studies that focused mostly on punitive strategies of 'othering' and in political domains, this study moves to the realm of tourism. This context has been chosen for various reasons. Firstly, tourism is one of the major global service industries with over one billion tourists travelling just in 2014 (UNWTO Tourism Highlights, 2014). Thus, it has a far-reaching impact on a vast number of people, yet the nature of this impact is rather one directional; despite the growth of tourism in the developing world, it is mostly the 'first world' people who can afford to travel to faraway destinations and there encounter local people who mostly cannot share this kind of experience. The inequality inherent to this 'contact' together with its cultural and linguistic differences makes tourism a prime site for the investigation of social categorisations and patterns of inclusion and exclusion (Heller et al., 2014). Secondly, the tourist experience is nowadays strongly driven by the desire for 'authentic' encounters, especially with local people and their alternative or 'primitive' ways of life (White, 2007). Although the notion of authenticity has been contested in tourism research (e.g. Cohen, 2007), commercial tourism materials focus heavily on the descriptions of supposedly 'real life and real people' and thus foreground authenticity and the figure of the local 'Other' (White, 2007). This warrants a closer examination of the representations of local people. Thirdly, strategies of 'othering' do not need to be based only on negative or punitive representations (Coupland, 2010). Patterns of dominance and exclusion can also be manifested in subtle ways and even through seemingly innocent or positive representations, for example, when the Other is ascribed some 'magical' qualities or is fetishized (Said, 1978). Promotional tourism discourse with its focus on 'real life and people' and images selected to develop positive attitudes towards destinations presents a compelling case to examine the ways in which social actors, especially local people, are represented.

The representations of local people in tourism discourse have been of interest to scholars working in the field of tourism studies. There is now a considerable body of research on the subject revealing the prevalence of stereotypic and homogenised images that tend to depict hosts as exotic, erotic, primitive and timeless, while local cultural diversity and modernity are 
This is a pre-publication version accepted for Corpora 2016, 11 (1) (in press). Please refer to the published version of this article if you wish to quote from it.

largely ignored (e.g. Cohen, 1993; Pritchard and Morgan, 2000; Aitchison, 2001; White, 2007; Kerrigan et al., 2012). This particularly applies to the images of developing countries that are heavily exoticised and projected as devoid of problems in order to make them more appealing to the 'tourist gaze' (Urry and Larsen, 2011). Interestingly, the practice of exoticising appears to be internalised by local tourism boards that, driven by economic gains, often reproduce an imagery similar to that disseminated by Western tourism companies (Kerrigan et al., 2012). In this sense and to borrow from Duchêne and Heller (2012), the 'pride' of local cultural distinction is downplayed by the perspective of 'profit'. Hence, many scholars see tourism generally as an industry that perpetuates colonial legacy and gendered discursive practices (Pritchard and Morgan, 2000; Aitchison, 2001; White, 2007; Thurlow and Jaworski, 2010b). However, this view has been recently contested by researchers who examined in more detail representations of local people and places in materials produced by local tourism boards. For example, Bandyopadhyay and Morais (2006) and Amoamo and Thompson (2010) have shown that self-representations focus more strongly on cultural diversity and modernity, and in doing so, challenge the dominant Western post-colonial representations. Contrary to the previous claim, these scholars believe that tourism can be a site of resistance.

While this new research has provided evidence for the existence of hegemonic and contradictory discourses about hosts in tourism discourse, its empirical basis has been, in most cases, small. With only a few exceptions (Bandyopadhyay and Morais, 2006), these studies are based on smaller samples of texts and examine the representations in a limited number of contexts, mostly one destination or region. This raises the issue of the generalisability of findings. Moreover, many of the studies make frequent references to linguistic concepts such as language, discourse or metaphor, but these tend not to be grounded in a systematic discourse-linguistic analysis. Unfortunately, linguists have shown little interest in the representations of hosts in tourism discourse, with the exception of work by Galasiński and Jaworski (2003), Jaworski et al. (2003b) and Kelly-Holmes and Pietikäinen (2014).

The present study intends to add to this strand of research by examining representations of hosts in a larger corpus of promotional tourist materials. Whereas previous linguistic studies on the subject are mostly sociolinguistically orientated and concerned with the role of languages in tourist-host interactions in single contexts, this study investigates written discourse of mass tourism, specifically texts describing 16 popular tourist destinations that at one point in their history had been colonised. Investigating texts produced for mass tourist 
This is a pre-publication version accepted for Corpora 2016, 11 (1) (in press). Please refer to the published version of this article if you wish to quote from it.

consumption is particularly relevant given the impact of these texts on the perceptions, expectations and decision-making behaviour of potentially a large number of tourists (Bandyopadhyay and Morais, 2006). In contrast to previous research that mostly adopted qualitative methodology, this study uses the framework of Corpus-Assisted Discourse Studies (CADS) (Partington, 2004; Partington et al., 2013) that combines quantitative corpus linguistic with qualitative discourse-analytical techniques. Since this study is interested in the representations of people, it also draws on a classification scheme of social actors proposed by van Leeuwen $(1996,2008)$. The specific questions which the present research addresses are:

1) How are hosts represented in tourism promotional materials produced by Western vs. local tourist industries?

2) To what extent do these representations differ?

3) What is the nature of the relationship between the representations found in the data and existing stereotypical, colonial, and often gendered, ideologies?

To this end, two corpora were created and examined. The first corpus, referred to as the External Corpus $(\mathrm{EC})^{2}$, contains promotional materials produced by some of the largest tourism organisations operating in Western Europe. The second corpus, the Internal Corpus (IC), includes promotional texts created by local tourism boards. By adopting the CADS methodology in combination with van Leeuwen's $(1996,2008)$ sociosemantic classification of social actors, this study attempts to empirically verify the extent to which colonial and gendered stereotypes reported in previous research are perpetuated or perhaps indeed resisted in contemporary tourism mass discourse and how such practices are negotiated linguistically. This study is also an example demonstrating how the CADS approach can be effectively used to verify or refine socio-cultural claims proposed in social sciences.

\section{Representations of hosts in tourism discourse}

The study of tourism as a linguistic and discursive practice is a relatively recent

\footnotetext{
${ }^{2}$ Most research concerned with the representations of local people refers to hosts as the 'Other'. Since this much depends on the positioning and context, for example, a tourist can also be the 'Other' (e.g. Kelly-Holmes and Pietikäinen, 2014), this study adopts the more broader terminology of external, that is, Western representations and internal, that is, representations projected by local tourism boards. Western is meant here in a geopolitical sense.
} 
This is a pre-publication version accepted for Corpora 2016, 11 (1) (in press). Please refer to the published version of this article if you wish to quote from it.

phenomenon. The first important contribution was Dann's (1996) analysis of the language of tourism. Since then, the research on tourism discourse has grown to include a variety of contexts, media and genres (e.g. Jaworski et al., 2003a; Jaworski et al., 2003b; Thurlow and Jaworski, 2003; Heller and Pujolar, 2009; Thurlow and Jaworski, 2010a; Thurlow and Jaworski, 2010b; Kelly-Holmes and Pietikäinen, 2014). These studies are mostly located in the field of Sociolinguistics and Social Semiotics and focused specifically on the role of languages and images in constructing the tourist experience. By drawing on concepts such as the commodification of language, language ideology and linguistic landscapes, this research sheds light on the multiple roles that linguistic and semiotic resources play in tourism marketing, for example, as markers of cultural distinction, 'authenticity' or difference.

The sociolinguistic interest in the role of (host) languages in tourism communication has also highlighted the importance of representations of local people. Two studies that deal specifically with this topic could be identified. By scrutinising 45 articles published in the Travel Section of the British broadsheet The Guardian in 1997, Galasiński and Jaworski (2003) identify three major categories in which hosts tend to be represented: 1) as a homogenous, ethnic or social group, 2) as prototypical representatives of 'national' or 'ethnic' group characteristics and 3) as 'featureless' servants or helpers. The homogenising effect is mainly achieved through the use of metonymy or generic terms of references that point to broad social categories, nationalities or locations. This contributes to the view of hosts as a uniform group without any traces of intergroup diversity or individualisation. The homogeneity is further reinforced through references to some supposedly typical and easily recognisable characteristics, for example, hosts are frequently described as 'friendly', 'helpful' and 'beautiful'. All in all, the ways in which hosts in tourist destinations are represented are restricted to a few selected images that construct them as 'unproblematic homogenous groups of people [...] odd but harmless, helpful but distant and subservient' (Galasiński and Jaworski, 2003: 145). Drawing on Foucault's notion of the regime of truths, the authors conclude that the representations of hosts in the travelogues reinforce the ideology of asymmetry which portrays 'us' (middle/upper class readers, journalists) as superior to the local people. This, combined with the image of hosts as 'exotic' and unproblematic, further perpetuates what Van Dijk (1993) calls 'elitist racist discourse' - a form of prejudiced discourse without being overtly prejudiced. Similar representations were identified in a subsequent study by Jaworski at al. (2003b), which focused on face-to-face encounters between reporters and local people in extracts from two British holiday TV programme series. By combining CDA with elements of Interactional Sociolinguistics, this 
This is a pre-publication version accepted for Corpora 2016, 11 (1) (in press). Please refer to the published version of this article if you wish to quote from it.

study, too, reveals a restricted image of local people reduced to the role of servants and on some occasions, experts.

Findings obtained from the discourse-analytical and sociolinguistic research seem to be in consonance with research on the representation of local people conducted in tourism studies. For example, White (2007) examines representations of Fijian people in a sample of Western tourist promotional materials. The analysis reveals that Fiji is consistently marketed as a space in which tourists can experience 'genuine' friendliness, warmth and sociability characteristics that local people are represented as having in abundance. Consistently, Fijians - mostly staff working in tourist resorts - are portrayed as easy going and carefree people who create an atmosphere of 'feeling' at home. In White's view, this constructs an affectionate servant-client relationship, which perpetuates a colonial imagery of the docility of local people. Although Fiji is a culturally and ethnically diverse island, only those who are deemed sufficiently 'exotic' are put on display for tourist consumption. For example, Fijian Indians, who make up $40 \%$ of the local population, are systematically erased from Fiji tourism discourse. The author argues that this discursive silence is caused by the image of Fiji Indians as being too individualist and business savvy - attributes that are too familiar to Western tourists and hence not exotic or authentic enough.

By combining postcolonialist theories with feminist critique and the notion of gendered spaces, Pritchard and Morgan (2000) investigate the representation of masculinity and femininity in tourist destinations. The researchers argue that tourist promotional materials perpetuate gendered ideologies in that they privilege the heterosexual male gaze. This comes into view in the different ways in which destinations in the North, South and East are portrayed. Whereas the North is normally seen as a wild place of adventure and activities mostly associated with men, the South and the East - especially the faraway destinations are persistently constructed as feminine, sensuous and seductive places awaiting masculine exploration. The sexualised imagery is often reinforced by frequent references to young girls that are "the most commonly occurring representation in the pages of Western travelogues and brochures' (ibid: 896). The authors conclude that the construction of gendered landscapes in tourism discourse does not only affirm the patriarchal and heterosexual norm; it also places contemporary tourism firmly within the tradition of colonialist and imperial discourses.

Most of the studies concerned with the representations of local people in tourism have examined Western perspectives, that is, texts and images produced by Western commercial tourism companies. Recently, researchers began to pay more attention to materials created by local tourism boards or ministries. Literature in this field reveals a mixed picture. For 
This is a pre-publication version accepted for Corpora 2016, 11 (1) (in press). Please refer to the published version of this article if you wish to quote from it.

example, Kerrigan et al. (2012) examines a small selection of pictures produced as part of the Incredible India campaign and concludes that they display 'authentic' India as imagined by Western tourists. By focusing on exotic dances, women and bright silk, the campaign engages in the process of exoticising local places and people, while aspects of modernity and the complexity of Indians' cultural identity are erased. The authors argue that in doing so, the Incredible India Campaign 'continues to reinforce a stereotypical, orientalist, and almost primitive snapshot of India' (ibid: 325).

While undoubtedly local tourism boards adopt some of the Western discursive practices not least because of the profit aspect (Duchêne and Heller, 2012), studies that examined a wider range of textual material point to different discourses. For example, Bandyopadhyay and Morais (2005) compare the representations of India in American tourist brochures and materials produced by India's governmental sources. They reveal a number of differences in the ways India and Indians are represented. Whereas American sources tend to depict Indians mostly as simple, poor and premodern, the internal representations are devoid of such images and focus more strongly on dynamism and modernity. In the view of the authors, the internal representations resist the dominant Western images of India as poor and powerless and in doing so, counteract colonialist fantasies.

Similarly, Amoamo and Thompson (2010) argue that tourism can act as a space for the dissemination of postcolonial counter-narratives. By carrying out interviews with Māori tourism operators and examining local tourist materials, the researchers show how tourist sites can develop into hybrid third spaces (Bhabha, 1994) that disrupt the dominant 'binary opposition between Western and 'native subjects, or colonized and colonizer' (Amoamo and Thompson, 2010: 38). The authors stress that tourism can afford a discursive space in which indigenous people can tell their version of the past and present, and communicate their own image of identity that resists the dominant Western representations.

Studies on the representations of local people in contemporary tourism discourse discussed so far suggests that there are two diverging discursive constructions. Consequently two conceptions of tourism discourse emerge: one which sees it as a space where difference is systematically maintained and the legacies of colonialism thrive, and one which points to its capacity as a site of resistance. While this research offers thought-provoking insights into the ways in which hosts are represented and provides some evidence for the existence of hegemonic discourses, there are some limitations. Firstly, the empirical basis of this research is small. Most of the studies are based on rather selective samples of texts often obtained from one specific source (e.g. The Guardian) and investigate singular contexts (e.g. India, 
This is a pre-publication version accepted for Corpora 2016, 11 (1) (in press). Please refer to the published version of this article if you wish to quote from it.

Fiji). The generalisability of the claims appears to be, therefore, a problematic issue. Also, most of the studies adopted the approach of Content Analysis but each operates with different coding categorisations, which, in turn, might raise some issues regarding reliability and validity (Macalister, 2011). Moreover, research on the subject conducted within the area of tourism studies tends to make frequent references to linguistic concepts such as language, discourse or metaphor, but is usually not grounded in a systematic discourse-linguistic analysis. At the same time and with the exception of the two studies above (Galasiński and Jaworski, 2003; Jaworski at al., 2003b), linguists have shown little interest in the patterns of the representations of local people in tourist destinations, despite extensive research on the representations of social actors in other domains. To my knowledge, there is also no linguistically orientated study that examines the representations of local people by comparing internal with external representations.

Such comparisons are important in that they could reveal not only the existence of hegemonic and normative discourses, but also the ways in which such discourses are contested and resisted. Undoubtedly, studying representations of the Other is a critical task that greatly increases our understanding of mechanisms of social stereotyping. Although the growing multi-ethnisation of modern societies combined with increasing mobility fosters hybridity in social relations, as Coupland remarks (2010: 257) there are 'no grounds to believe that the practice of group-level ideological representation will weaken or cease.' This is because social representations are central to our social cognition (Tajfel, 1981). At the same time, the problem with research concerned with the other-representations is its focus on the one side of the story only, which may overlook the existence of discourses that could potentially "mitigate the stereotype of the stereotype" (Cohen, 1993: 65). Comparing otheror external with self- or internal representations can add new perspectives and show patterns of representations that a single analysis of other-representations cannot reveal. This is precisely what the present study attempts to demonstrate. Before discussing the main research findings, the next section outlines the methodology and the data sets under scrutiny.

\section{Methodology and Corpus Data}

The methodology adopted for this study follows the framework of Corpus-Assisted Discourse Studies (CADS) (Partington 2004; Partington et al., 2013). In contrast to qualitative approaches to discourse, CADS integrates quantitative methods of Corpus Linguistics to uncover salient and less salient meanings in larger amounts of textual data 
This is a pre-publication version accepted for Corpora 2016, 11 (1) (in press). Please refer to the published version of this article if you wish to quote from it.

(Partington et al., 2013). The benefit of Corpus Linguistics lies in its capacity to reveal repetitively occurring lexico-grammatical patterns, which, in turn, can point to salient representations and the majority ways of viewing the phenomena under investigation (Baker, 2008). As Stubbs (2001: 215) highlights: 'Repeated patterns show that evaluative meanings are not merely personal or idiosyncratic, but widely shared in a discourse community. A word, phrase or construction may trigger a cultural stereotype.' Since cultural stereotypes are precisely the concern of this study, CL can offer methodological tools useful for the current investigation.

Whereas Corpus Linguistics sensu stricto favours quantitative analysis and mainly heterogenic corpora, CADS is particularly interested in specialised types of discourse (Partington et al., 2013). In contrast to other approaches that integrate Corpus Linguistics with discourse-analytical procedures (e.g. Baker, et al. 2008), CADS is much more eclectic in nature and not focused on a particular type of discourse analysis, for example CDA. In fact, it encourages researchers to draw on as many analytical tools, frameworks and contextual information as it may be required to obtain the most complete picture. CADS is also suitable for this study due to its comparative credo. As Partington et al. (2013: 12) observe, 'we are not deontologically justified in making statements about the relevance of a phenomenon observed to occur in one discourse type unless [...] we compare how the phenomenon behaves elsewhere.' Comparisons can take different forms. We can compare one discourse type in different sources, for example, national print newspapers vs. online commentaries (e.g. Vessey 2013a). Another type of comparison is a diachronic one, which allows the researcher to identify discursive shifts over time (e.g. Marchi, 2010; Taylor, 2010). We can also study a discourse type produced under different circumstances or in different cultural and geographical locations - a type of comparison which this study follows.

The CADS approach has been effectively used to study representations in different contexts, for example, representations of nationalism in Canada (Vessey, 2013a, 2013b), the representations of Islam and Muslims in the British media (Baker et al., 2013) and the portrait of immigrants in the British and Italian press (Taylor, 2014). This study adds yet another context to this body of research, that of tourism, which has not been previously investigated using the CADS methodology.

In order to address the research questions outlined in the Introduction, two corpora - an External Corpus (EC) and an Internal Corpus (IC) - were created consisting of promotional tourism materials. The EC includes texts produced by some of the largest tourism corporations operating in Western Europe including Thomson Holidays (part of TUI - the 
This is a pre-publication version accepted for Corpora 2016, 11 (1) (in press). Please refer to the published version of this article if you wish to quote from it.

world's largest tourism company), Virgin Holidays, Thomas Cook, Sandals and Kuoni Travel. The texts were manually sourced from the companies' websites (see Appendix I) and describe the most popular destinations as indicated on the company's websites during the time of data collection (April 2013). These produced the following list of sixteen destinations: Cuba, Dominican Republic, Egypt, India, Indonesia, Jamaica, Kenya, Malaysia, Maldives, Mauritius, Namibia, Nepal, South Africa, Sri Lanka, Thailand and Vietnam. Appendix II shows the number of tokens obtained from each travel company and for each destination. Since this research was interested in post-colonial discursive practices, Southern European destinations that were listed amongst the most popular ones were not included in the corpus because they were not colonised in the early modern period. The list of destinations is, by no means, exhaustive. However, it was felt that the focus on the most popular destinations points to texts that are likely to have a wider impact. Also, the corpus includes destinations from a variety of regions and in this way, it is not skewed towards a particular area, which, unlike previous studies that have focused on one country or region only, allows for more general claims to be made. To ensure comparability of the data, only texts that describe the destinations and its main regions and towns were sourced from the websites. Texts describing specific resorts or hotels were excluded, as was travel information.

It should also be noted that each company targets slightly different audiences. For example, Kuoni and Sandals are specialists in luxury holidays, whereas Thomson Holiday and Virgin also offer cheaper all-inclusive packages. The companies also produce texts of different lengths. Despite the differences, the overall style of the descriptions is rather similar, pointing perhaps to the generic homogenising tendencies of mass communication (Van Leeuwen 2008). As the example of Caribbean destinations in Appendix III shows, the texts included in the EC display prototypical characteristics of commercial tourism discourse including a heavy use of adjectives often in the superlative form, the pronoun 'you', imperatives, languaging and metaphors (Dann, 1996). Thus, the present study treats all the texts as representative of the Western commercial tourism discourse and examines them as such.

To create the Internal Corpus, promotional tourism materials from the official tourism websites produced by local tourism boards or ministries of the 16 countries were sourced. As with the EC, the IC includes only descriptions of the countries and its tourist regions and towns. As Table 1 demonstrates, the IC with 242,889 tokens is three times larger than the EC. This reflects the amount and scope of information available on the websites with the local tourism boards producing longer and more detailed descriptions. Although having similar- 
This is a pre-publication version accepted for Corpora 2016, 11 (1) (in press). Please refer to the published version of this article if you wish to quote from it.

size corpora is, in many ways, better in comparative research, as it helps avoid some of the pitfalls of normalised frequencies, it was felt that cutting the corpora to achieve the same size would compromise the context and the discourse of the local tourism boards in that some valuable textual data could have been lost. Appendix II lists the number of tokens for each destination in the IC.

Table 1: Size of the Corpora

\begin{tabular}{l|r} 
Corpus & Tokens \\
\hline External Corpus (EC) & 82,959 \\
Internal Corpus (IC) & 242,889
\end{tabular}

Both corpora were searched using the software Sketch Engine (Kilgarriff et al., 2004). Since social actors are most likely to be referred to by nouns, in the first instance the most frequent nouns in singular and plural in both corpora were retrieved. The lists were then carefully examined to identify the most frequent lexical items used to refer to local people. These were subsequently categorised into sociosemantic groups using Caldas-Coulthard and Moon's adaptation (2010) of Van Leeuwen's $(1996,2008)$ categorisation scheme of social actors.

In his comprehensive analysis of the ways in which social actors can be represented in English, Van Leeuwen $(1996,2008)$ reminds us that language users have a pool of grammatical and lexical choices at their disposal from which they can select items to name and describe people. It is important to remember that their choices are never neutral and more often than not project a vision of reality which reflects certain ideological stances (Van Dijk, 1995). In the first instance, social actors or certain groups of social actors may be included or excluded. If included, there are three major ways in which people can be categorised: 1) functionalisation, 2) identification and 3) appraisement. Functionalisation refers to the categorisation of people in terms of an activity and what they do, whereas identification is a way of describing people in terms of "what they, more or less permanently, or unavoidably, are' (Van Leeuwen, 1996: 54). Here, he distinguishes three sub-categorisations: classification, relational identification and physical identification. Classification entails general social categories such as age, gender, ethnicity, nationality, religion or sexual orientation. Relational identification categorises people in accordance with their relations with others, whereas physical identification includes physical attributes related to appearance, size etc. The last category - appraisement - entails evaluative and affective terms. Whereas 
This is a pre-publication version accepted for Corpora 2016, 11 (1) (in press). Please refer to the published version of this article if you wish to quote from it.

functionalisation, classification and relational identification can be identified by studying nouns referring to social agents, words occurring in the vicinity of the nouns, that is, their collocations can tell us a great deal about the physical, evaluative and affective attributes. Thus, the most frequent nouns referring to local people were selected and their collocational profiles investigated using LogDice as a metric of collocation strength and a -5 and $5+$ span.

\section{The Representations of Hosts}

In the first instance lists of the most frequent nouns including nouns in singular, plural and proper nouns were extracted from both corpora (see Table 2). Since proper nouns were mostly names of places, this category was excluded from further analysis.

Table 1: Number of nouns in both corpora

\begin{tabular}{l|r|r} 
& \multicolumn{1}{|l|}{ EC } & \multicolumn{1}{l}{ IC } \\
\hline Nouns Singular (NN) & 11,907 & 34,115 \\
\hline Nouns Plural (NNS) & 5,974 & 16,758 \\
\hline Proper Nouns Singular (NP) & 6,724 & 28,522 \\
\hline Proper Nouns Plural (NPS) & 74 & 236
\end{tabular}

Table 3 shows the ten most frequent singular (NN) and plural nouns (NNS) in each corpus with their raw (RF) and normalised frequencies (NF). Already these short lists point to some similarities and differences between the two data sets. Whereas the most frequent nouns in the EC refer to elements of landscape ('beach', 'island') and tourist facilities ('hotels', 'restaurants'), the IC includes references to 'history', 'culture' and 'people'.

Table 3: The most frequent singular (NN) and plural nouns (NNS) in both corpora

\begin{tabular}{l|r|r|l|r|l|l|r|r|l|r|r}
\multicolumn{9}{c|}{ EC } & \multicolumn{7}{c}{ IC } \\
\hline NN & RF & NF & NNS & RF & NF & NN & RF & NF & NNS & RF & NR \\
\hline beach & 269 & 32.4 & beaches & 233 & 28.1 & city & 388 & 16.0 & people & 284 & 11.7 \\
\hline island & 225 & 27.1 & holidays & 185 & 22.3 & world & 364 & 15.0 & visitors & 232 & 9.6 \\
\hline holiday & 166 & 20.0 & sands & 135 & 16.3 & island & 353 & 14.5 & years & 204 & 8.4 \\
\hline city & 158 & 19.0 & hotels & 125 & 15.1 & country & 291 & 12.0 & beaches & 195 & 8.0 \\
\hline world & 141 & 17.0 & waters & 118 & 14.2 & town & 279 & 11.5 & species & 161 & 6.6 \\
\hline life & 121 & 14.6 & restaurants & 113 & 13.6 & temple & 237 & 9.8 & areas & 147 & 6.1 \\
\hline resort & 120 & 14.5 & resorts & 101 & 12.2 & time & 218 & 9.0 & attractions & 145 & 6.0 \\
\hline place & 110 & 13.3 & islands & 72 & 8.7 & history & 212 & 8.7 & islands & 141 & 5.8 \\
\hline coast & 105 & 12.7 & bars & 70 & 8.4 & life & 211 & 8.7 & mountains & 123 & 5.1 \\
\hline
\end{tabular}


This is a pre-publication version accepted for Corpora 2016, 11 (1) (in press). Please refer to the published version of this article if you wish to quote from it.

\begin{tabular}{l|l|l|l|l|l|l|l|l|l|l|l}
\hline home & 94 & 11.3 & shops & 55 & 6.6 & culture & 185 & 7.6 & hotels & 116 & 4.8
\end{tabular}

Subsequently, all nouns that occurred more than three times in each corpus were examined in order to identify the most frequent references to local people. As in some cases the references could describe other groups (for example, the term 'people' was also used to denote tourists), concordance lines were carefully examined and only the instances when the term referred to the local population were included and counted. When the references occurred in both singular and plural, the forms were counted together.

There were twenty unique references to local people in the EC and sixty eight in the IC. When comparing the relative frequencies of the results, it becomes apparent that local people are nearly four times more frequently mentioned in the materials produced by the local tourism boards than in the texts supplied by the Western tourism corporations. There is also a greater variety of terms. As Table 4 shows, in the EC the hosts are mostly referred to by the two generic descriptors, 'locals' and 'people', and are associated with lower status occupations such as 'fisherman' and 'butler'. In contrast, the IC contains in addition to the generic term 'people' very different terms. These refer to gender ('man/men', 'woman/women'), religion ('devotees'), history ('ancestors') and higher status professions ('artist').

Table 4: The 10 most frequent references to local people

\begin{tabular}{l|r|r|l|r|r}
\multicolumn{2}{c|}{ EC } & \multicolumn{4}{c}{ IC } \\
\hline Reference & RF & NF & Reference & RF & NF \\
\hline locals & 33 & 4.0 & people & 184 & 7.6 \\
\hline people & 32 & 3.9 & man/men & 81 & 3.4 \\
\hline fisherman/fishermen & 12 & 1.4 & woman/women & 65 & 2.7 \\
\hline butler/butlers & 11 & 1.3 & tribe/tribes & 60 & 2.5 \\
\hline man/men & 6 & 0.7 & devotees & 57 & 2.3 \\
\hline hawker/hawkers & 5 & 0.6 & children & 51 & 2.1 \\
\hline dancer/dancers & 4 & 0.5 & pilgrims & 49 & 2.0 \\
\hline hunter/hunters & 4 & 0.5 & artist/artists & 44 & 1.8 \\
\hline residents & 4 & 0.5 & inhabitants & 41 & 1.7 \\
\hline tribe/tribes & 4 & 0.5 & Hindus & 37 & 1.5
\end{tabular}

A subsequent classification of all the references in accordance with the adapted version of Van Leeuwen's $(1996,2008)$ classification scheme highlights the differences in the representations even more. Table 5 shows that in the EC local people are predominantly described by references to occupations of lower status or jobs that are associated with serving 
This is a pre-publication version accepted for Corpora 2016, 11 (1) (in press). Please refer to the published version of this article if you wish to quote from it.

and a traditional way of life ('butlers', 'hunters', 'hawkers'). The second most frequent category is that of provenance; if local people are not referred to by their low occupations, then they are mostly described in terms of their generic location as 'locals' or 'inhabitants'.

Table 5: Classification of references to local people in the EC

\begin{tabular}{l|l|r|r} 
Category & Reference & $\begin{array}{r}\text { Total } \\
\text { Tokens/RF }\end{array}$ & NF \\
\hline OCCUPATION & $\begin{array}{l}\text { fisherman/men }(12 / 1.4)^{3} \text { butler }(11 / 1.3) \\
\text { craftsmen }(4 / 0.5) \text { hawker/s }( \\
5 / 0.5) \text { dancer/s }(4 / 0.5) \text { hunters (4/0.4) } \\
\text { artisan/s (3/0.4) farmers (3/0.4) } \\
\text { merchants (3/0.4) musicians (3/0.4) } \\
\text { traders (3/0.5) }\end{array}$ & 55 & 6.6 \\
& $\begin{array}{l}\text { locals (33/4.0) residents (4/0.5) } \\
\text { inhabitants (3/0.4) islanders (3/0.4) } \\
\text { natives (3/0.4) }\end{array}$ & 46 & 5.5 \\
\hline PROVENANCE & people (32/3.9) & 32 & 3.9 \\
\hline GENERIC TERMS & tribe/s (4/0.5) communities (3/0.4) & 7 & 0.8 \\
\hline RELATIONSHIP & men/man (6/0.7) & 6 & 0.7 \\
\hline GENDER & & 146 & 17.6
\end{tabular}

Different patterns can be observed in the IC (see Table 6). Here, we have a greater number and diversity of categories and terms. The largest category includes historical and political references, mostly to powerful roles in the structure of society such as 'king', 'emperor' or 'warriors'. This highlights the fact that the countries included in the IC have a long history of being organised societies - something which was omitted in the EC.

Table 6: Classification of references to local people in the IC

\begin{tabular}{|c|c|c|c|}
\hline Category & Reference & $\begin{array}{r}\text { Total } \\
\text { Tokens RF }\end{array}$ & NF \\
\hline $\begin{array}{l}\text { POLITICS/HIST } \\
\text { ORY }\end{array}$ & $\begin{array}{l}\text { king/s (134/5.5) ancestor/s (35/1.4) slaves } \\
(32 / 1.3) \text { ruler/s }(21 / 0.9) \text { emperor }(13 / 0.5) \\
\text { governor }(13 / 0.5) \text { soldiers }(13 / 0.5) \text { leader/s } \\
(12 / 0.5) \text { warriors }(11 / 0.5) \text { founder }(8 / 0.3) \\
\text { descendants }(9 / 0.4) \text { Mughals }(4 / 0.3)\end{array}$ & 305 & 12.6 \\
\hline OCCUPATION & $\begin{array}{l}\text { artist/s }(44 / 1.8) \text { traders }(27 / 1.1) \text { author/s } \\
(20 / 0.8) \text { athletes }(19 / 0.8) \text { poet/s }(17 / 0.7) \\
\text { farmers }(17 / 0.7) \text { artisans }(14 / 0.6) \text { dancers } \\
(14 / 0.6) \text { musician/s }(13 / 0.5) \text { scientists }(12 / 0.5) \\
\text { runners }(10 / 0.4) \text { professionals }(9 / 0.4)\end{array}$ & 287 & 11.8 \\
\hline
\end{tabular}

\footnotetext{
${ }^{3}$ The first number in the bracket is the raw frequency and the second refers to the normalised frequency per 10,000 .
} 
This is a pre-publication version accepted for Corpora 2016, 11 (1) (in press). Please refer to the published version of this article if you wish to quote from it.

\begin{tabular}{|c|c|c|c|}
\hline & $\begin{array}{l}\text { craftsmen }(9 / 0.4) \text { writer/s }(9 / 0.4) \text { historian/s } \\
(8 / 0.3) \text { labourers }(8 / 0.3) \text { hunters }(8 / 0.3) \\
\text { director }(6 / 0.2) \text { painters }(6 / 0.2) \text { producer } \\
(5 / 0.2) \text { chefs }(4 / 0.2) \text { experts }(4 / 0.2) \\
\text { entrepreneurs }(4 / 0.2)\end{array}$ & & \\
\hline RELIGION & $\begin{array}{l}\text { devotees (57/2.3) pilgrims (49/2.2) Hindus } \\
\text { (37/1.5) Buddhists }(24 / 1.0) \text { monks }(12 / 0.5) \\
\text { Muslims (11/0.5) Christians }(5 / 0.2)\end{array}$ & 195 & 8.0 \\
\hline $\begin{array}{l}\text { GENERIC } \\
\text { TERMS }\end{array}$ & people $(184 / 7.6)$ & 184 & 7.6 \\
\hline GENDER & $\begin{array}{l}\text { man/men }(81 / 3.4) \text { woman/women }(65 / 2.6) \\
\text { girl/s }(16 / 0.7) \text { boy/s }(11 / 0.5)\end{array}$ & 173 & 7.1 \\
\hline KINSHIP & $\begin{array}{l}\text { son/s (69/2.8) child/children (51/2.1) mother } \\
(26 / 1.1) \text { father/s }(13 / 0.5) \text { brother/s }(11 / 0.5)\end{array}$ & 170 & 7.0 \\
\hline PROVENANCE & $\begin{array}{l}\text { inhabitants (41/1.7) locals (35/1.4) residents } \\
(30 / 1.2)\end{array}$ & 106 & 3.8 \\
\hline $\begin{array}{l}\text { SOCIAL } \\
\text { RELATIONSHIP }\end{array}$ & $\begin{array}{l}\text { tribe/s }(60 / 2.5) \text { citizens }(11 / 0.5) \text { comrades } \\
(5 / 0.2)\end{array}$ & 76 & 3.1 \\
\hline NATIONALITY & $\begin{array}{l}\text { Mauritians (11/0.5) Nepalis (11/0.5) } \\
\text { Egyptians (9/0.4) Indians (7/0.3) Kenyans } \\
(6 / 0.2) \text { Cubans (4/0.2) Malaysians }(5 / 0.2) \\
\text { Indonesians (5/0.2) South Africans (4/0.2) } \\
\text { Jamaicans (4/0.2) }\end{array}$ & 66 & 2.7 \\
\hline Total & & 1,562 & 64.3 \\
\hline
\end{tabular}

Interestingly, we find here references to 'slave' and 'slaves'. The context in which these references are used points mostly to the suffering and hardship endured by local people during colonial times. Example 1-3 illustrate this:

1) The oral traditions associated with these runaways have made Le Morne a symbol of the slaves' fight for freedom, their suffering and their sacrifice. (Mauritius)

2) Unique in Latin America, the former San Severino Castle was built by the slave labor force. It now exhibits pieces, documents and objects that support the horrors of slavery. (Cuba)

3) Children born of slaves automatically became the property of the slave owner and thus it was that many of those born as a result of this miscegenation, were exposed to the Christian religion and the culture of their "owners". (Malaysia)

The term 'slaves' is also used in the EC but only two times. The context in which the two references occur tend to evoke positive associations such as music and singing or is related to 
This is a pre-publication version accepted for Corpora 2016, 11 (1) (in press). Please refer to the published version of this article if you wish to quote from it.

events that are seen as 'positive consequences', for example, the ability to speak English. Below are the two examples:

4) Sega - a rousing dance with vibrant flowing fabrics and uplifting music, originally sung by slaves. And the food here is divine. (Kuoni, Mauritius)

5) It was originally settled by a couple of shiploads of American slaves, and to this day many of the locals speak English as their first language. (Thomson, Dominican Republic)

Local tourist industries frequently portray local people also in terms of occupations, which is the second largest category identified. However, whereas in the EC the occupations represented low-status services, those listed in Table 6 appear to be linked with local cultures and heritage, and point mostly to professions of higher intellectual standing. There is only one instance of 'hawker' in the IC, which refers specifically to food courts in Malaysia.

The third largest sociosemantic category is that of religion. Here we find a range of terms pointing to religious identity of hosts and their participation in sacral or spiritual events ('pilgrims', 'devotees'). In the EC references to religious identity are rare with 'Muslim' being mentioned only once and in relation to a specific religious custom. The term 'devotees' occurs also once but with reference to 'designer label devotees' in the context of shopping. Other terms within the domain of religion are absent in the EC.

There is also another striking difference between the two data sets: the use of gendered terms. Whereas in the EC references pointing to gender are almost absent, this category seems quite salient in the IC (see Table 5) and hence worth further examination.

In the IC, there are forty-two instances of the singular form 'man' and forty-six of 'men'. In comparison, we find only three instances of 'man' and three of 'men' in the EC. In the IC, the singular 'man' is either used as a generic term subsuming all humans and living creatures or points to a famous male personality, a king or leader (see Figure 1). There were also five examples of 'man' used in proper names such as River Man or in novel titles e.g., The Old

\section{Man and the Sea.}

Figure 1: Concordances of 'man' in the IC

history. From the prehistoric records of early man to the present day, Kenya has been a land sacrifice every full moon, until a brave water that supports the entire region, both chosen as the cradle of the earliest known man from Morocco, Mr Abdul Barakaath-Ul Barbary

man and animal alike. Water-loving creatures

man . Sabaragamuwa the aboard of homo sapien 
This is a pre-publication version accepted for Corpora 2016, 11 (1) (in press). Please refer to the published version of this article if you wish to quote from it.

one time or another home to prehistoric man and its descendents. There are also many

The use of the generic 'man' is from the perspective of gender equality condemned as an example of male bias, as it reflects a gender belief system that makes females and female contribution invisible (Hellinger and Bußmann, 2001). As recently shown by Baker (2014) in a study on American English, since the early $19^{\text {th }}$ century there has been a steady decline in the use of the generic 'man' in this variety. The Western tourist materials reflect this trend too in that the generic 'man' is used only once. The more frequent use of this generic in the IC suggests that promotional materials produced by local tourist agencies perpetuate, to some extent, the male-orientated vision of the world and history.

The plural form 'men' shows a different pattern of usage. It occurs 45 times, of which 12 occurrences are a binominal pair 'men and women' (see Figure 2):

Figure 2: Concordances of the binominal pair 'men and women' in the IC ements but burst with verve and vitality. Men and women perform some dances exclusively, while exclusively, while in some performances men and women dance together. On most occasions, the ion of India has its own folk dance. Both men and women perform the bamboo dance of Mizoram.

to their legs and dance to music. Both men and women perform this form of art. In Tamil Nadu purpose wrap around cloth worn by both men and women . At the waters edge is Fort Jesus, an

All instances of the binominal pair occur in the context of performing local cultural customs, and mainly dances. The use of 'men' before 'women' is not surprising and reflects the patterns of 'male firstness' observed in English (Baker, 2014: 92). In the EC, we find only three instances of the plural 'men' and only one example of the binominal 'men and women'.

The singular 'woman' occurs only three times, one of which points to Indira Ghandi as the first and only female Prime Minister of India. Otherwise, the term is used only in plural (sixty two times). Examining the most frequent collocations of 'men' and 'women' yields further insights into gendered distinctions. As Table 7 shows, 'women' tend to be associated with clothing, beauty and items pointing to a traditional way of life, whereas 'men' collocates with 'young' and 'work'.

Table 7: Collocations of 'men' and 'women' in the IC

\begin{tabular}{l|l} 
men & $\begin{array}{l}\text { women (11.898), perform (11.219), young (11.210), numbers (10.476), work } \\
\text { (9.857), European (9.857) }\end{array}$ \\
\hline women & men (11.718), worn (11.522), baskets (11.172), perform (10.791), beautiful
\end{tabular}


This is a pre-publication version accepted for Corpora 2016, 11 (1) (in press). Please refer to the published version of this article if you wish to quote from it.

(9.778), colourful $(9.122)$

The concordances below are representative examples of such associations (see Figure 3):

Figure 3: Concordances of 'women' in the IC

, and the streets always come alive with women selling their jewellery, baskets, garments is always heavy with the scent of spices. Women wearing the traditional buibui fill the ose wrap around cloth worn by both men and women . At the waters edge is Fort Jesus, an imposing worn around the shoulders by both men and women . The beading worn by the Maasai is also varieties of beadwork, traditionally made by women to be worn by both women and men. As a

In the EC, there is only one instance of the singular 'woman', which refers to a famous female ruler from the $14^{\text {th }}$ century. Otherwise, local women are not identified.

It is also important to note that the gendered terms are not equally distributed across the IC. As Table 7 shows, the terms 'woman/women' appear to be more frequently mentioned in the marketing of Namibia, Kenya and India and absent from materials describing South Africa, Sri Lanka, Cuba, Dominican Republic and Egypt. The terms 'man/men' are used in almost all descriptions except Dominican Republic and Egypt. Here too, the marketing of destinations such as Namibia, Jamaica and India seems to make greater use of 'man/men' than in case of Vietnam or Mauritius.

Table 8: Distribution of 'man/men' and 'woman/women' in the IC

\begin{tabular}{|c|c|c|c|c|c|c|c|}
\hline \multicolumn{4}{|c|}{ man/men } & \multicolumn{4}{|c|}{ woman/women } \\
\hline Destination & Tokens & Hits & $\begin{array}{c}\text { NF per } \\
1,000\end{array}$ & Destination & Tokens & Hits & $\begin{array}{c}\text { NF per } \\
1,000\end{array}$ \\
\hline Namibia & 16,994 & 15 & 0.88 & Namibia & 16,994 & 12 & 0.71 \\
\hline Jamaica & 5,928 & 5 & 0.84 & Kenya & 22,009 & 15 & 0.68 \\
\hline India & 19,154 & 12 & 0.63 & India & 19,154 & 12 & 0.63 \\
\hline Maldives & 3,296 & 2 & 0.61 & Mauritius & 20,512 & 5 & 0.24 \\
\hline Kenya & 22,009 & 11 & 0.50 & Malaysia & 13,447 & 3 & 0.22 \\
\hline Cuba & 19,301 & 9 & 0.47 & Indonesia & 18,828 & 4 & 0.21 \\
\hline Malaysia & 13,447 & 6 & 0.45 & Nepal & 23,164 & 5 & 0.22 \\
\hline Indonesia & 18,828 & 6 & 0.32 & Thailand & 19,201 & 4 & 0.21 \\
\hline Thailand & 19,201 & 6 & 0.31 & Vietnam & 15,257 & 3 & 0.20 \\
\hline Sri Lanka & 15,889 & 4 & 0.26 & Jamaica & 5,928 & 1 & 0.17 \\
\hline South Africa & 14,312 & 3 & 0.21 & & & & \\
\hline Nepal & 23,164 & 4 & 0.17 & & & & \\
\hline Mauritius & 20,512 & 3 & 0.15 & & & & \\
\hline Vietnam & 15,257 & 2 & 0.13 & & & & \\
\hline
\end{tabular}


This is a pre-publication version accepted for Corpora 2016, 11 (1) (in press). Please refer to the published version of this article if you wish to quote from it.

Promotional tourist materials, those portraying faraway destinations in particular, have been criticised for disseminating sexualised images through a heavy focus on local women especially young girls (Pritchard and Morgan, 2000). Since no instances of the lemma 'girl' could be identified in the EC, this study cannot confirm this tendency. Does it mean that the Western representations are becoming less gendered and less sexualised? This would be a very encouraging development. There is some evidence to suggest that the Western public and media are becoming more aware of gendered representations and some parity has been achieved in media representations over the last few decades (e.g. Jaworska and Larrivée, 2011). However, there is no doubt that sexist biases prevail (Baker, 2014). As to the EC, an absence of gendered terms, especially references to women, seems to indicate that there is a lesser focus on sexualised images. However, it needs to be borne in mind that the texts included in the corpus mostly describe luxury holidays and target affluent tourists, often families. This could partially explain the absence of sexualised images. To further substantiate the claim, it would be necessary to examine materials that aim at younger audiences and advertise tourist destinations in other locations, for example, in Southern Europe (e.g. Baker, 2006). At the same time, it is surprising to see a greater number of gendered terms in the IC and the differences in the ways in which men and women are portrayed. The representations appear to perpetuate gender asymmetries and a maleorientated view of the world and history (Kerrigan et al., 2012), though arguably not all destinations are projected in this way. The position of women in those destinations that seem to make a greater use of gendered terms is marked by deep inequalities. However, women have achieved some gains, for example, their visibility in political, public and professional domains in some of the societies (e.g. India, Mauritius) has grown. This is, however, omitted from the internal representations that tend to associate modernity, culture and sophistication with men and traditional way of life with women.

Finally, the most frequent references to local people used in both corpora were selected and their collocational profiles studied in order to shed light on the two remaining categories of Van Leeuwen's classification scheme: physical identification and appraisement. The references selected from both corpora include 'people' and 'locals'. Although the term 'locals' was not very frequent in the IC, it was chosen for the sake of comparability.

In the EC, the terms 'locals' and 'people' are used thirty-three and thirty-two times respectively (see Table 4). The frequencies of both terms amount to nearly half of all the tokens used to describe local people in this data set. Given the small amount of occurrences, there were only a few collocates, of which the four most frequent are shown in Table 9. 
This is a pre-publication version accepted for Corpora 2016, 11 (1) (in press). Please refer to the published version of this article if you wish to quote from it.

Table 9: Collocates of 'locals' and 'people' in the EC locals $\quad$ friendly (11.167), popular (10.142), where (9.167), with (9.152) people friendly (11.356), hospitable (10.752), welcoming (10.752), who (10.608)

As can be seen, in this data set local people are mostly attributed with friendliness and are represented as 'hospitable' and 'welcoming'. This largely confirms patterns revealed in previous studies (White, 2007; Gałasinski and Jaworski, 2003). As Gałasinski and Jaworski (2003) observe, representing local people as inherently friendly and hospitable is part of their romanticisation, which simultaneously evokes an image of the local Other as unafraid and perhaps a little bit naïve, but certainly someone who creates a safe environment. White (2007) takes it further and argues that local people are fetishised in this way, which, in turn, re-creates the colonialist image of local communities as docile and unthreatening.

In the IC, the term 'people' occurs 184 times as a reference to the local population (see Table 4), while 'locals' is used comparatively less - thirty five times. Table 10 shows the five most frequent collocates of both terms.

Table 10: Collocates of 'people' in the IC

people $\quad$ local (10.207), nation (10.159), hospitality (10.142), million (10.030), culture $(9.395)$

locals $\quad$ alike (11.519), tourists (10.839), favourite (10.563), popular (9.568), international (9.281)

While the internal representations also point to hospitality as a feature of local people, this is the only evaluative attribute occurring in the vicinity of 'people'. There is no other frequent mention of friendliness or other forms of sociability. The other collocates refer mainly to facts that affected the local community throughout the history. For example, the collocate 'million' is a reference to the number of workers who were transported to former colonies, while 'nation' refers to the process of nation building and the unity of local communities. The importance of history and integrity becomes evident when we examine the patterns surrounding the phrase 'local people'. As the concordance lines in Figure 4 below demonstrate, 'local people' are mostly represented as participants in the social, cultural and political life of their communities:

Figure 4: Concordances of 'local people' in the IC 
This is a pre-publication version accepted for Corpora 2016, 11 (1) (in press). Please refer to the published version of this article if you wish to quote from it.

recognition for the history made by the local people with its participation in the different enhance the cultural integrity of local people . Therefore, in addition to evaluating envir environment and improves the well-being of local people. This means that those who implement financial benefits and empowerment for local people Raise sensitivity to host countries' political a thriving centre for the local Samburu people, and the streets always come alive with

In contrast, the representations of 'locals' in the EC create an image of local people as passive elements of a beautiful landscape or inherently friendly and happy humans (see Figure 5).

Figure 5: Concordances of 'locals' in the EC cocktail or just the glorious sunshine, but the locals are always happy and smiling and it's very A plethora of birdlife, warm and friendly locals, waters that teem with vibrant marine life this island lovely conjours up images of locals limin' on the beach, rum punch in hand, the year round, combined with the friendly locals, the wonderfully warm bathing waters, and the snaking stretch of sun-kissed sand, locals smiling as they offer you trinkets and

This stands in contrast to the representation of 'locals' in the IC, in which the word tends to collocate with items such as 'tourists' 'favourite' and 'popular' (see Table 10). A quick look at concordance lines shows that these items represent 'locals' as active agents who like tourists travel and enjoy the local tourist places (see Figure 6).

Figure 6: Concordances of 'locals' in the IC

of the street, is very popular among the locals and a great example of Santiago's relaxed Bali has been the favorite destination for locals and international tourists for ages. Full others. Nasitimbel is a favorite among locals and visitors. Batagorbasotahugoreng rolling hills, a popular destination for locals, especially on public holidays. Local that draws international visitors and locals alike in great numbers, the annual Maralal

In summary, the collocational profile of 'people' and 'locals' in the EC tends to portray the hosts as docile, friendly and smiley servants and thus, appears to reproduce the ideological colonial asymmetry. In contrast, the internal representations seem to place the local people on an equal footing with tourists and in this way, dismantle the colonial imagery of the inferior status and subservience of hosts.

\section{Conclusions}


This is a pre-publication version accepted for Corpora 2016, 11 (1) (in press). Please refer to the published version of this article if you wish to quote from it.

As observed by Van Leeuwen (1996), text producers have a pool of grammatical and lexical choices at their disposal from which they can select items to name and describe people. Their choices are never neutral; in naming and describing social actors, they select some aspects of reality which propagates a vision aligned with their ideological stance. By referring to the local population with the generic 'people' and foregrounding their friendliness, the Western tourist industry promotes a homogenised image of hosts as unproblematic and obedient. Any signs of individuality or diversity are erased. Moreover, through the frequent references to low status occupations and activities associated with serving, hosts are persistently 'functionalised' (Van Leeuwen, 1996) as servants for the tourist. They are not only positioned as inferior, but it seems that their existence is solely justified through their service for the tourist. Indicators of modernity and dynamism are conveniently erased to fit the stereotype of exotic faraway destinations as unspoilt and uncivilised. In doing so, the seemingly positive and innocent images reinforce the ideology of asymmetry (Galasiński and Jaworski, 2003) and perpetuate the colonialist imagery of primitive but docile inhabitants just there to serve either directly as waiters or as human scenery. While this claim has already been suggested by a number of scholars (Atchison, 2001; Galasiński and Jaworski, 2003; White, 2007), this study provided quantitative evidence that such imagery is recreated consistently and systematically in descriptions portraying faraway destinations.

The analysis also corroborated a claim put forward by Bandyopadhyay and Morais (2005) and Amoamo and Thompson (2010) that tourism discourse can be a site of resistance. As demonstrated, the internal representations appear to resist the dominant Western imagery by focusing on local ethnic and religious diversities and emphasising dynamism and modernity. The representations of local people in a variety of high status roles and functions disrupt the Western image of timelessness and primitivism. As the analysis showed, local tourism boards also use the discursive space afforded by tourism to engage in a critical assessment of the colonial past, especially slavery, something which is brushed over or glamorised in the Western representations.

This study has also demonstrated a much more nuanced picture that defies the black and white scenarios proposed in literature. The Western representations of local people have been criticised for reinforcing gendered and sexualised images through a focus on women, especially young girls. Yet, the present analysis cannot confirm this claim. References to gender are absent from the texts produced by Western companies. On the contrary, they feature more prominently in the internal representations, especially in those of Kenya, 
This is a pre-publication version accepted for Corpora 2016, 11 (1) (in press). Please refer to the published version of this article if you wish to quote from it.

Namibia and India. When they appear, they seem to associate women with low status occupations, dancing and clothes, and men with power and authority. This creates a representative dissonance, to borrow from Bandyopadhyay and Morais (2005). While the internal representations seem to resist the colonialist imagery of local people as simple and powerless, in some cases they reinforce these through the representations of women in subordinate positions.

All in all, the analysis demonstrates a number of benefits of a comparative CADS approach to the study of representations. The integration of quantitative corpus-linguistic tools with qualitative discourse-analytical techniques such as van Leeuwen's $(1996,2008)$ sociosemantic inventory and a closer reading of concordance lines allowed the researcher to identify the dominant ways in which social actors are systematically represented in the two discursive contexts. Comparing the two contexts did, in turn, shed light on discursive dissonances and proved useful in verifying and refining some of the claims suggested in previous literature. In other words, the CADS approach helped put things into perspective. However, there are also some limitations. Although the current study used a larger amount of data than previous qualitative studies, the corpus is limited to the descriptions of mostly tropical destinations that share a particular history, that of colonisation. Further research could include destinations from other parts of the world to assess whether the ideology of asymmetry and male bias prevail in other contexts too. Also future research would need to go beyond the text. Given that images are an integral part of tourism promotional discourse, further studies would need to complement a quantitative textual analysis with a multimodal approach based on a systematic examination of the visual material in order to reveal other semiotic resources. Work by Thurlow and Jaworski (2010) on silence in tourism discourse and the semiotic approach to visual design by Kress and Van Leeuwen (1996) provide conceptual tools for such an analysis, though indisputably, a combination of semiotic analysis with corpus-linguistic techniques remains a methodological and technical challenge. Lastly, given the growing importance of social media for promoting and expressing tourist experiences, future research would need to focus on tourism discourse in online environments. Maci's (2013) work on digital voices of tourism is a constructive step in this direction. 
This is a pre-publication version accepted for Corpora 2016, 11 (1) (in press). Please refer to the published version of this article if you wish to quote from it.

\section{References}

Aitchison, C. 2001. 'Theorizing Other discourses of tourism, gender and culture. Can the subaltern speak (in tourism)?',Tourist Studies 1 (2), pp. 133-147.

Amoamo, M. and A. Thompson. 2010. '(Re)Imaging Maori tourism: Representation and cultural hybridity in postcolonial New Zealand', Tourist Studies 10 (1), pp. 35-55.

Baker, P. 2008. Using Corpora in Discourse Analysis. London: Continuum.

Baker, P. 2014. Using Corpora to Analyse Gender. London: Bloomsbury.

Baker, P. and McEnery, T. 2005. 'A corpus-based approach to discourses of refugees and asylum seekers in UN and newspaper texts', Journal of Language and Politics, 4(2), pp. 97-226.

Baker, P., C. Gabrielatos and T. McEnery. 2013. Discourse analysis and media attitudes: the representation of Islam in the British press. Cambridge: Cambridge University Press.

Baker, P., C. Gabrielatos, M. KhosraviNik, M. Krzyzanowski, T. McEnery and R. Wodak. 2008. 'A useful methodological synergy? Combining critical discourse analysis and corpus linguistics to examine discourses of refugees and asylum seekers in the UK press', Discourse \& Society 19 (3), pp. 273-306.

Bandyopadhyay, R. and D. Morais. 2005. 'Representative dissonance. India's Self and Western image', Annals of Tourism Research 32 (4), pp. 1006-1021.

Bhabha, H. 1994. The Location of Culture. London: Routledge.

Caldas-Coulthard, C. and R. Moon. 2010. 'Curvy, hunky, kinky': Using corpora as tools for critical analysis', Discourse \& Society 21 (2), pp. 99-133.

Cohen, E.1993. 'The study of touristic images of native people: mitigating the stereotype of a stereotype' in D. Pearce and R. Butler (eds.) Tourism Research. Critiques and Challenges, pp. 36-69. London: Routledge.

Cohen, E. 2007.'Authenticity in Tourism Studies: Apreś la Lutte', Tourism Recreation Research 32 (2), pp. 75-82.

Coupland, N. 2010. ' Other' representation', in J. Jaspers, J. Östmanand J. Verschueren (eds.) Society and Language Use, pp. 241-260. Amsterdam: Benjamins.

Dann, G.1996. The Language of Tourism: A Sociolinguistic Perspective. Wallingford: CAB International.

Duchêne, A. and M. Heller. 2011. Pride and Profit: Language in Late Capitalism. Oxford, U.K.: Routledge.

Gabrielatos, C. and P. Baker. 2008. 'Fleeing, sneaking, flooding: a corpus analysis of discursive constructions of refugees and asylum seekers in the UK Press 1996-2005', Journal of English Linguistics 36 (1), pp. 5-38.

Galasiński, D. and A. Jaworski. 2003. 'Representations of Hosts in Travel Writing: The Guardian Travel Section', Tourism and Cultural Change 1 (2), pp. 131-149.

Hardt-Mautner, G.1995. 'Only Connect: Critical discourse analysis and corpus linguistics', UCREL Technical Paper 6. Lancaster: University of Lancaster. http://ucrel.lancs.ac.uk/tech_papers.html

Heller, M. and J. Pujolar. 2009. 'The political economy of texts: A case study in the structuration of tourism', Sociolinguistic Studies 3, pp. 177-202.

Heller, M., A. Jaworski and C. Thurlow. 2014. 'Introduction: Sociolinguistics and tourism mobilities, markets, multilingualism', Journal of Sociolinguistics 18 (4), pp. 425-458.

Hellinger, M. and H. Bußmann.2001.'Gender across languages. The linguistic representation of women and men' in A. Hellinger and H. Bußmann (eds.) Gender across Language, pp. 119-133. Amsterdam: Rodopi.

Jaworska, S. 2013. 'The quest for the 'local' and 'authentic': Corpus-based explorations into the discursive constructions of tourist destinations in British and German commercial 
This is a pre-publication version accepted for Corpora 2016, 11 (1) (in press). Please refer to the published version of this article if you wish to quote from it.

travel advertising' in D. Höhmann (ed.) Tourismuskommunikation. Im Spannungsfeld von Sprach- und Kulturkontakt, pp. 75-100. Frankfurt am Main: Peter Lang.

Jaworska, S. and P. Larrivée. 2011. 'Women, power and the media. Assessing the bias', Journal of Pragmatics 43, pp. 2477-79.

Jaworski A., C. Thurlow, S. Lawson and V. Ylänne-M'E Ewen. 2003b. 'The uses and representations of local languages in tourist destinations: A view from British TV holiday programmes', Language Awareness 12(1), pp. 5-29.

Jaworski, A., V. Ylänne-M'Ewen, C. Thurlow and S. Lawson.2003a. 'Social roles and negotiation of status in host-tourist interactions. A view from a British television holiday programme', Journal of Sociolinguistic 7 (2), pp. 135-163.

Kelly-Holmes, H. and S. Pietikäinen. 2014. 'Commodifying Sámi culture in an indigenous tourism site', Journal of Sociolinguistics 18 (4), pp. 518-538.

Kerrigan, F., J. Shivanandanand A. Hede.2012. 'Nation Branding: A Critical Appraisal of Incredible India', Journal of Macromarketing32 (3), pp. 319-327.

Kilgarriff, A., P. Rychly, P. Smrz and D. Tugwell. 2004. 'The Sketch Engine', Proc EURALEX 2004, pp. 105-116. Lorient: France.

Kress, G. and T. van Leeuwen. 1996. Reading Images: The Grammar of Visual Design. London: Routledge.

Krishnamurthy, R. 1996. 'Ethnic, racial and tribal: The language of racism?' in C. Caldas Coulthard and M. Coulthard (eds.) Texts and Practices: Readings in Critical Discourse Analysis, pp. 129-149. London: Routledge.

Macalister, J. 2011. 'Flower-girl and bugler-boy no more: changing gender representation in writing for children', Corpora 6 (1), pp. 25-44.

Marchi, A. 2010. 'The moral in the story: a diachronic investigation of lexicalised morality in the UK press', Corpora 5 (2), pp. 161-189.

Maci, S. 2013. Tourism Discourse: Professional, Promotional and Digital Voices. Genova: ECIG.

Partington, A. 2004. 'Corpora and discourse, a most congruous beast', in A. Partington, J. Morley and L. Haarman (eds.) Corpora and Discourse, pp. 9-18. Frankfurt/M: Peter Lang.

Partington, A., A. Duguid and C. Taylor. 2013. Patterns and Meanings in Discourse. Theory and Practice in Corpus-Assisted Discourse Studies (CADS). Amsterdam/Philadelphia: Benjamins.

Pritchard, A. and N. Morgan. 2000. 'Privileging the male gaze: Gendered tourism landscapes', Annals of Tourism Research 27 (4), pp. 884-905.

Said, E. 1978. Orientalism. London: Routledge \& Kegan Paul.

Stubbs, M. 2001. Words and Phrases: Corpus Studies of Lexical Semantics. Oxford: Blackwell.

Tajfel, H. 1981. 'Social stereotypes and social groups' in J. Turner and H. Giles (eds.) Intergroup Behaviour, pp. 144-165. Oxford: Blackwell.

Taylor, C. 2014. 'Investigating the representation of migrants in the UK and Italian press: A cross-linguistic corpus-assisted discourse analysis', International Journal of Corpus Linguistics 19(3), pp. 368-400.

Taylor, C. 2010. 'Science in the news: a diachronic perspective', Corpora 5 (2), pp. 221-250.

Thurlow, C. and A. Jaworski. 2003. 'Communicating a global reach: Inflight magazines as a globalising genre in tourism', Journal of Sociolinguistics 7 (4), pp. 579-606.

Thurlow, C. and A. Jaworski.2010a. 'Silence is Golden: The 'Anti-communicational' Linguascaping of Super-elite Mobility', in A. Jaworski and C. Thurlow (eds.) Semiotic Landscapes: Language, Image, Space, pp. 187-218. London: Continuum. 
This is a pre-publication version accepted for Corpora 2016, 11 (1) (in press). Please refer to the published version of this article if you wish to quote from it.

Thurlow, C. and Jaworski, A. 2010b.Tourism Discourse. Language and Global Mobility. Basingstoke: Palgrave Macmillan.

Urry, J. and J. Larsen. 2011. The Tourist Gaze 3.0. ( $3^{\text {rd }}$ Edition). London: Sage.

Van Dijk, T. 1993. Elite Discourse and Racism. London: Sage.

Van Dijk, T. 1995. 'Discourse semantics as ideology', Discourse \& Society 6 (2), pp. 243 289.

Van Leeuwen, T. 1996. 'The representation of social actors' in C. Caldas-Coulthard and M. Coulthard (eds.) Texts and Practices: Readings in Critical Discourse Analysis, pp. 32-70. London: Routledge.

Van Leeuwen, T. 2008. Discourse and Practice. New Tools for Critical Discourse Analysis. Oxford: Oxford University Press.

Vessey, R. 2013a. 'Too much French? Not enough French?: The Vancouver Olympics and a very Canadian language ideological debate', Multilingua 32 (5), pp. 659-682.

Vessey, R. 2013b. 'Challenges in cross-linguistic corpus-assisted discourse studies', Corpora 8 (1), pp. 1-26.

White, C. 2007. 'More authentic than thou: Authenticity and othering in Fiji tourism discourse', Tourist Studies 7 (1), pp. 25-49.

World Tourism Organisation (UNWTO). 2014. Tourism Highlights, 2014 Edition. http://mkt.unwto.org/publication/unwto-tourism-highlights-2014-edition [last accessed 25 March 2015].

Appendix I:

Addresses of websites for which texts were sourced to build the External Corpus (EC)

Kuoni Travel: $\quad$ http://www.kuoni.co.uk/

Thomson Holidays: http://www.thomson.co.uk/

Virgin Holidays: $\quad$ http://www.virginholidays.co.uk/

Thomas Cook: $\quad$ https://ww2.thomascook.com/

Sandals: $\quad$ http://www.sandals.co.uk/

Addresses of websites for which texts were sourced to build the Internal Corpus (IC)

Cuba: $\quad$ http://www.cuba-travel.tur.cu

Egypt: $\quad$ http://www.egypt.travel/

Dominican Republic: http://www.dominicanrepublic.com/

India: $\quad$ http://www.incredibleindia.org

Indonesia: $\quad$ http://www.indonesia.travel/

Jamaica: $\quad$ http://www.visitjamaica.com/

Kenya: $\quad$ www.magicalkenya.com

Malaysia: $\quad$ http://www.tourism.gov.my/en/uk

Maldives: $\quad$ http://www.visitmaldives.com/en

Mauritius: $\quad$ http://www.tourism-mauritius.mu

Namibia: $\quad$ http://www.namibiatourism.com.na/

Nepal: $\quad$ http://welcomenepal.com/promotional/

South Africa: $\quad$ http://country.southafrica.net/country/uk/en/

Sri Lanka: $\quad$ http://www.srilanka.travel/index.php?route=common/home

Thailand: $\quad$ http://www.tourismthailand.org/ 
This is a pre-publication version accepted for Corpora 2016, 11 (1) (in press). Please refer to the published version of this article if you wish to quote from it.

Vietnam: $\quad$ http://www.vietnamtourism.com/

Appendix II

\begin{tabular}{|l|r|}
\hline Travel Company & $\begin{array}{l}\text { No. of } \\
\text { tokens in } \\
\text { EC }\end{array}$ \\
\hline Kuoni & 36,103 \\
\hline Thomson & 25,407 \\
\hline Virgin Holidays & 12,473 \\
\hline Sandals & 6,862 \\
\hline Thomas Cook & 2,114 \\
\hline Total & 82,959 \\
\hline
\end{tabular}

\begin{tabular}{|l|r|r|}
\hline Destination & $\begin{array}{l}\text { No. of } \\
\text { tokens in } \\
\text { EC }\end{array}$ & $\begin{array}{l}\text { No. of } \\
\text { tokens in } \\
\text { IC }\end{array}$ \\
\hline Cuba & 5,033 & 19,301 \\
\hline Egypt & 5,070 & 6,391 \\
\hline Dominican Republic & 5,907 & 9,233 \\
\hline India & 5,916 & 19,154 \\
\hline Indonesia & 4,545 & 18,828 \\
\hline Jamaica & 8,364 & 5,928 \\
\hline Kenya & 5,211 & 22,009 \\
\hline Malaysia & 4,075 & 13,447 \\
\hline Maldives & 4,361 & 3,269 \\
\hline Mauritius & 5,897 & 20,512 \\
\hline Namibia & 3,262 & 16,994 \\
\hline Nepal & 3,080 & 23,164 \\
\hline South Africa & 5,866 & 14,312 \\
\hline Sri Lanka & 5,267 & 15,889 \\
\hline Thailand & 6,419 & 19,201 \\
\hline Vietnam & 4,686 & 15,257 \\
\hline Total & 82,959 & 242,889 \\
\hline
\end{tabular}

Appendix III: Descriptions of Caribbean Destinations included in the EC

Kuoni, Cuba

"You cannot think of Cuba as another Caribbean holiday, it's a once in a lifetime experience. It has the magic to transport you to Colonial times, The Fifties and then back to modern day. Picture yourself in a ' 57 Chevrolet, riding along the famous Malecon to Al Capone's favourite hotel, The Nacional. Watch the sun go down over the bay from a privileged viewpoint in the hotel's gardens while sipping one of Hemingway's favourite cocktails, the world famous "Mojito"."

Sandals, Jamaica 
This is a pre-publication version accepted for Corpora 2016, 11 (1) (in press). Please refer to the published version of this article if you wish to quote from it.

"Welcomed by the cool sea breeze, the moment you walk into the open-air lobby of this Montego Bay beach resort you know that you have arrived at the perfect vacation paradise. Set along the Jamaica's best private white-sand beach, Sandals Montego Bay offers guests an authentic laid-back Caribbean experience and the lively vibe of the islands. Here, the blues are as far as the eye can see and the fun never ends."

Thomas Cook, Cuba

"Cuba holidays offer a delicious cocktail of stunning beaches, Latin rhythms and modern living. Cuba is an incredible destination where visitors are greeted with the impressive colonial architecture of Havana, a relaxed atmosphere and rumba beats. Sip daiquiris and listen to the salsa while watching 1950s American cars chug by, or get out and see Havana's crumbling facades."

Thomson, Caribbean destinations

"If you thought holidays in the Caribbean were all about sun, sea and sand, think again. Although you'll be hard pushed to beat this mesmerising destination for its pristine beaches, clear sparkling shores and glorious weather conditions, not to mention its sheer snorkelability and excellent scuba-diving opportunities around some of the most beautiful reefs in the world, holidays in the Caribbean offer a lot more than suntans and swimming."

Virgin Holidays, Cuba

"A holiday in Cuba is like no other you will have experienced. Being the biggest island in the Caribbean, Cuba offers everything you'd associate with this gorgeous little corner of the world: sea, sun, sand and a laid back vibe. However, there's something very different about Cuba, something that sets it apart. Maybe it's the island's extraordinary history, its political system, its decades of self-sufficiency in the face of global controversy, its unique Afro-Latin culture - whatever it is, it certainly makes Cuba one of the most intriguing holiday destinations in the world." 